This item was submitted to Loughborough's Research Repository by the author.

Items in Figshare are protected by copyright, with all rights reserved, unless otherwise indicated.

\title{
Effect of sterilisation by gamma irradiation on the ability of polycaprolactone (PCL) to act as a scaffold material
}

PLEASE CITE THE PUBLISHED VERSION

PUBLISHER

(C) Elsevier

VERSION

AM (Accepted Manuscript)

LICENCE

CC BY-NC-ND 4.0

\section{REPOSITORY RECORD}

Cottam, Emily, David W.L. Hukins, Kenneth Lee, Christopher J. Hewitt, and Mike J. Jenkins. 2010. "Effect of Sterilisation by Gamma Irradiation on the Ability of Polycaprolactone (PCL) to Act as a Scaffold Material". figshare. https://hdl.handle.net/2134/5762. 
This item was submitted to Loughborough's Institutional Repository (https://dspace.lboro.ac.uk/) by the author and is made available under the following Creative Commons Licence conditions.

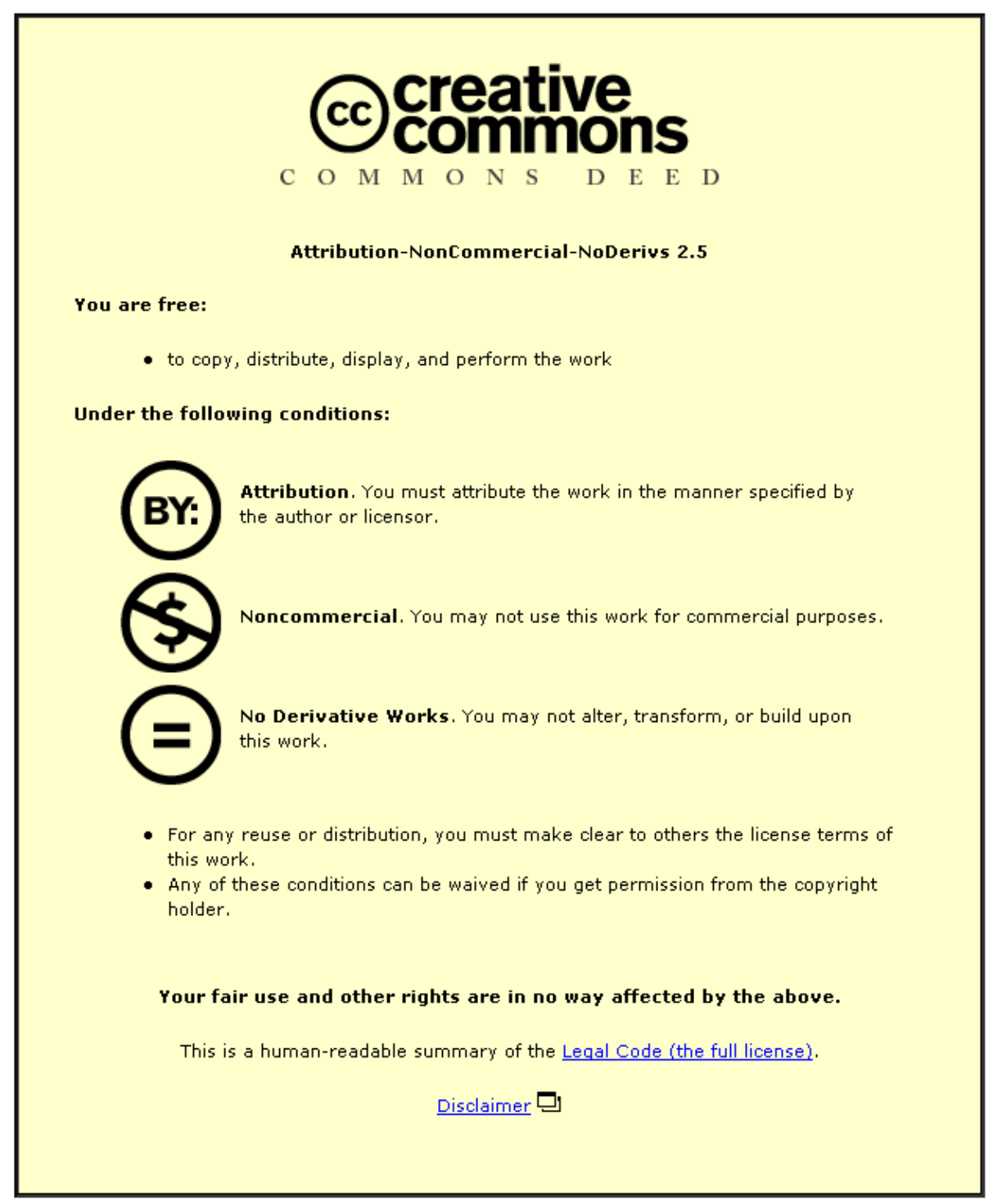

For the full text of this licence, please go to: http://creativecommons.org/licenses/by-nc-nd/2.5/ 
Effect of sterilisation by gamma irrradiation on the ability of polycaprolactone (PCL) to act as a scaffold material

E. Cottam ${ }^{\text {a,b* }}$ (corresponding author; fax:, email: exc086@bham.ac.uk)

D. W. L. Hukins ${ }^{\text {b }}$ K. Lee ${ }^{c}$, C. Hewitt ${ }^{\text {c, d }}$ and M. J. Jenkins ${ }^{a}$

${ }^{\mathrm{a}}$ Metallurgy \& Materials Science

${ }^{\mathrm{b}}$ Mechanical Engineering

${ }^{\mathrm{c}}$ Chemical Engineering

School of Engineering, University of Birmingham, Edgbaston, Birmingham B15 2TT, UK.

${ }^{\mathrm{d}}$ Department of Chemical Engineering, University of Loughborough, Loughborough, Leicestershire, LE11 3TU, UK.

* Corresponding author. Email: exc086@,bham.ac.uk. Fax number: 01214143958 


\begin{abstract}
Polycaprolactone (PCL) is a promising potential material for tissue engineering scaffolds. This paper investigates the effect of sterilisation by gamma irradiation (dose 2.5 Mrad) on degradation rate (catalysed by lipase), mechanical properties and the ability of cells to attach and subsequently grow on its surface. Gel permeation chromatography (GPC) was used to determine the effects of gamma irradiation of weight average, $M_{w}$, and number average, $M_{n}$, molecular weights. Gamma irradiation significantly decreased the rate of degradation, although the rates depended on the initial mass of polymer. It also significantly altered the mechanical properties, increasing the yield stress. PCL failed in tension by three different mechanisms. Irradiation significantly increased the failure stress, when the failure mechanisms were considered separately but not when they were combined. It caused a significant increase in $M_{w}$ and decrease in $M_{n}$ that could be attributed to chain scission and crosslinking. Chondrocyte attachment and growth on PCL was not significantly affected by gamma irradiation.
\end{abstract}

\title{
Keywords
}

Cell proliferation; Degradation; Mechanical properties; Polycaprolactone; Scaffold; Sterilisation. 


\section{Introduction}

Polycaprolactone (PCL) is a resorbable polymer that has been used to make surgical implants and tissue engineering scaffolds [1-4]. One of its advantages is that it has a slower rate of hydrolysis than the competitor materials polyglycolic acid (PGA) and polylactic acid (PLA) [1].

Gamma irradiation is a common technique for sterilising polymeric implants [5] and is likely to be the method of choice for many PCL implants [6]. If tissue engineering is to develop as a practical method, e.g. for surgical repair of tissues, it will be necessary to sterilise scaffolds by methods that are conventionally used for other implants. Scaffolds usually have porous structures [2-4], so a sterilisation method is required that can penetrate such a material without leaving residues that could, for example, affect the ability of cells to attach and grow. Gamma irradiation is highly penetrative. However, it is not known whether it affects the ability of cells to attach and grow on PCL.

There has been little research performed into how sterilisation, especially from gamma irradiation, can affect the properties of PCL. Narkis et al (1985) found that gamma irradiation induced chain scission and cross-linking [7], but their work focussed mainly on much higher doses than that required for sterilisation. Masson et al (1997) used the standard sterilisation dose of $25 \mathrm{kGy}$ but were concerned only with PCL nanospheres [8]. 
The important properties for a bioresorbable scaffold are its rate of degradation, its mechanical strength and the ability to support cell growth [2]; the effect of gamma irradiation on these properties is the subject of this paper. In addition, gel permeation chromatography (GPC) was used to investigate the extent of chain scission and crosslinking following gamma irradiation, in order to determine plausible mechanisms for any changes in properties. Mechanical strength is important for any application where the tissue has a mechanical role in the body (as is the case for most connective tissues, e.g. cartilage) or is subjected to appreciable mechanical loads. Finally, it is essential for a scaffold material to have suitable surface properties for cells to attach and proliferate.

\section{Materials and methods}

\subsection{Preparation of films}

PCL (Grade TONE ${ }^{\mathrm{TM}}$ P787; Dow Chemicals, Middlesex) in the form of pellets. Films were prepared using a heated press (Model E1127; Moore, Bridgeport, CT, USA) at $200^{\circ} \mathrm{C}$ and 15 tonnes pressure for two minutes. The dimensions of the films depended on the experiments to be performed (see Sections 2.3, 2.5 and 2.7).

\subsection{Sterilisation by gamma irradiation}

The standard dose for sterilisation by gamma irradiation is $2.5 \mathrm{Mrad}$ (25 kGy) (ISO 11137-2:2006). However, in practice, this dose is usually exceeded, to ensure 
thorough sterilisation, and a certified dosage of $30.8 \mathrm{kGy}$, at a commercial facility, was used in our experiments (Isotron, Daventry, Northants, UK).

\subsection{Degradation}

A wad-press cutter (Fisher Scientific, town, Leicestershire, UK) was used to cut discs (diameter $10 \mathrm{~mm}$, thickness $0.5 \mathrm{~mm}$ ) from the PCL films produced using the method described in section 2.1. A total of 16 discs were used; 8 of these were irradiated.

It was necessary to accelerate the degradation of PCL, in order to complete the experiments in a reasonable time, because PCL can take up to 2 years to degrade appreciably $[9,10]$; we have observed a loss of mass of $0.001 \mathrm{~g}$ of PCL discs in phosphate buffered saline (PBS) during a period of 13 months. Lipase from Pseudomonas cepacia has been used as a catalyst for this purpose [1].

Lipase (Grade 62309, 50 units/mg; Sigma-Aldrich, Poole, Dorset, UK) was dissolved in phosphate-buffered saline (Sigma-Aldrich, Poole, Dorset, UK) at a concentration of $7 \mathrm{mg} / \mathrm{ml}$. A sample $(5 \mathrm{ml})$ of this solution was added to each of 16 tubes. The mass of each PCL disc was then determined (to within $0.001 \mathrm{~g}$ ); each disc was then placed in a tube of solution. The tubes were labelled and sealed and placed in a water bath at $37^{\circ} \mathrm{C}$.

The samples were removed, touch-dried with a paper towel and weighed after 1, 2, 4, 7, 24 hours and then every 24 hours until the mass of the samples remained constant. 


\subsection{Scanning electron microscopy}

Scanning electron microscopy was used to examine some of the PCL discs after the degradation studies had been completed. Specimens were coated with gold before and examined in a scanning electron microscope (Model 6300, Jeol Ltd, Welwyn Garden City, Herts, UK).

\subsection{Tensile testing}

Tensile test pieces (dumbbell-shaped with a shaft length $27 \mathrm{~mm}$, width $4 \mathrm{~mm}$ and thickness $1.5 \mathrm{~mm}$ ) were cut from PCL sheets of PCL made by the method described in Section 2.1. Samples were tested to failure, in tension, at a rate of $100 \mathrm{~mm} / \mathrm{min}$ using a computer-controlled testing machine (Model 6000R, with a $1 \mathrm{kN}$ load cell; J.J. Lloyd, Fareham, Hants, UK). This rate was chosen because it gave consistent results and the tests could be performed in around 15 minutes. The test pieces were marked at the clamps so that any slippage could have been detected and the results rejected. Results from samples that did not break in the shaft of the test piece were rejected. The numbers of valid results are listed in Table 1 . Nominal stress and strain were calculated from the initial length of the clamped test piece (measured with a ruler) and the shaft width and thickness (measured with callipers).

\subsection{Gel permeation chromatography}

GPC was performed by Rapra Technology (Shrewsbury, Shropshire, UK). A solution of each sample was prepared using chloroform as a solvent and adding $10 \mathrm{ml}$ to 20 
mg of the sample and allowing at least 4 hours to dissolve. The solutions were then thoroughly mixed and filtered through a $0.2 \mu \mathrm{m}$ polyamide membrane. The flow-rate used was $1.0 \mathrm{~mL} / \mathrm{min}$ at a temperature of $30^{\circ} \mathrm{C}$. The data was collected and analysed using Trisec 2000 and Trisec 3.0 software (Viscotek, Berkshire, UK). The weightaverage molecular weight $\left(M_{w}\right)$ and number-average molecular weight $\left(M_{n}\right)$ of the PCL were calibrated using standard polystyrene samples.

\subsection{Cell proliferation}

Discs (diameter of $32 \mathrm{~mm}$ ) were cut from PCL sheets made by the method described in Section 2.1. They were assigned to three groups (each consisting of 20 discs). One group was sterilised by gamma irradiation (Section 2.2). The second group was sterilised by soaking in ethanol ( $70 \%$ for 15 minutes). The third group was sterilised by both methods. Each disc was fixed to the bottom of a well (in a six-well plate) using silicon vacuum grease to prevent them lifting [11].

Bovine chondroprogenitor cells (Smith and Nephew Research Centre, York, UK) were isolated from confluent cultures at Passage 4, according to the method described in Malero-Martin et al (2005)[12]. Preliminary experiments were undertaken to determine cell attachment, and by analysing the medium at regular intervals, it was discovered that all the cells attached to the PCL discs within 1 hour of seeding.

Cells were seeded onto the PCL discs at a density of $10^{4}$ cells $/ \mathrm{cm}^{2}$. Growth medium (500 $\mu \mathrm{L}$ of Opti-MEM supplemented with $2 \%$ foetal bovine serum, $2.7 \mathrm{mM} \mathrm{CaCl}_{2}, 25$

$\mu \mathrm{g} / \mathrm{mL} L$-ascorbate-2-monophosphate; Sigma-Aldrich Poole, Dorset, UK) with a 
penicillin/streptomycin mix (Invitrogen, Paisley, UK) was used, as described in Graff et al (2002)[13]. A sample of the medium $(3 \mathrm{ml})$ was added to each of the wells the cells were cultured in incubator at $37^{\circ} \mathrm{C}$ with $5 \% \mathrm{CO}_{2}$ for 10 days. The medium was changed every two days.

At regular intervals $(24 \mathrm{~h})$, two discs were removed from each group. Cells were removed by immersion in trypsin $(0.5 \mathrm{~g} / 100 \mathrm{ml}$ PBS $) /$ EDTA $(0.2 \mathrm{~g} / 100 \mathrm{ml}$ PBS $)$ for 15 minutes at $37^{\circ} \mathrm{C}$ and $5 \% \mathrm{CO}_{2}$. The cell sample was then centrifuged at $100 \mathrm{rpm}$ for 5 minutes and then re-suspended in $1000 \mathrm{ml}$ of PBS.

Absolute and viable cell counts were performed using a flow cytometer. Densities were found by adding $20 \mu \mathrm{l}$ of the cell sample to $250 \mu \mathrm{l}$ of phosphate buffered saline and $20 \mu \mathrm{l}$ of Flowcheck Fluorosphere Beads (Beckman Coulter, High Wycombe, Bucks, UK) and run through an Epics Elite Flow cytometer with argon ion excitation at 488nm (Beckman Coulter, High Wycombe, Bucks, UK) [14]. Cell viability was assessed by adding $10 \mu \mathrm{l}$ of propidium iodide (Sigma-Aldrich, Poole, Dorset, UK) and $3 \mu \mathrm{l}$ of calcein AM (Invitrogen, Paisley, UK) to $250 \mu \mathrm{l}$ of the trypsinised cell sample [15]. Each sample was then analysed by through flow cytometry in duplicate.

\subsection{Statistical methods}

The Anderson-Darling test was used to determine whether data was normally distributed. If the data was normally distributed, then a two sample $t$-test was used to test for significant differences. If the data was not normally distributed, then a Mann- 
Whitney test was employed. Minitab (Release 14, Minitab Inc., State College, Pennsylvania, USA) was used for these calculations.

Cell growth curves were analysed using the Regression Wizard in SigmaPlot (Version 9.0, Systat Software Inc., Hounslow, London, UK). For each group, there were two replicates at each time period; their mean was used in all analyses. For each group, the number of cells was divided by the number at an initial time period of $24 \mathrm{~h}$, to aid the comparison of results. The distribution of data points did not justify fitting a sigmoid curve to the data points [16] but they could be fitted satisfactorily by a straight line. The standard error of each slope was used to calculate upper and lower $95 \%$ confidence intervals.

\section{Results}

\subsection{Degradation}

Figure 1 shows that degradation of both gamma irradiated and untreated PCL discs was greatest during the first 10 hours. As the degradation progressed, the rate continued to slow until the masses of the discs remained constant.

The degradation did not have a simple order of reaction. However, a straight line was obtained by plotting the square root of mass against the square root of time (Figure 2). A separate line was plotted for each PCL disc, i.e. 8 lines were obtained for gamma irradiated discs and 8 lines for untreated discs. Lines were plotted for degradation times of up to 168 hours after which the mass was almost constant. The slopes of the 
lines for the untreated samples $\left(-0.0170 \pm 0.0018 \mathrm{~g}^{1 / 2} / \mathrm{h}^{1 / 2}\right.$, mean \pm standard deviation) were significantly $(p<0.001)$ steeper than those for the irradiated samples $(-0.0136 \pm$ $\left.0.009 \mathrm{~g}^{1 / 2} / \mathrm{h}^{1 / 2}\right)$.

At the end of the experiment, what remained of the samples from the irradiated and non-irradiated groups looked different. While the non-irradiated samples had smooth edges, the irradiated samples had rough, flimsy edges which were more difficult to handle. This can be seen in the scanning electron micrographs shown in Figure 2.

\subsection{Tensile Tests}

The samples failed by three different mechanisms, described as: drawn, non-drawn and part-drawn. Figure 3 explains the difference between the three mechanisms. The numbers of specimens failing by each mechanism are shown in Table 1 . The different failure mechanisms lead to a large variation in the results, so when examining the tensile properties of non-irradiated and irradiated samples the three different mechanisms were compared separately.

Results for irradiated and untreated PCL are compared at the yield and failure points (Figure 4). The yield point is defined as the point of maximum stress before irreversible deformation takes place. The failure point is defined as the point at which the sample breaks.

Table 2 shows that irradiation significantly increases the yield strength of PCL, irrespective of the mechanism of failure. However, irradiation has no significant 
effect on the yield strain (Table 3). When the different failure mechanisms are considered separately, Table 4 shows that irradiation significantly increases the failure stress; however, when failure mechanisms are not distinguished, there is no significant difference. Table 5 shows that, for drawn and part-drawn failure modes, irradiation significantly increases the failure strain; otherwise there is no significant difference.

There was an obvious difference in appearance between the irradiated and the nonirradiated test pieces. When they were stretched, the opaque samples soon became transparent. However, while the non-irradiated samples became uniformly transparent, the irradiated samples were left with opaque patches.

\subsection{Gel Permeation Chromatography}

Table 6 shows that irradiated samples have a significantly higher $(p<0.01)$ weight average molecular weight, $M_{w}$, and a significantly lower $(p<0.01)$ number average molecular weight, $M_{n}$, than untreated samples. This result means that the irradiated samples were significantly more $(p<0.01)$ polydispersed than the untreated samples [17], as shown in Table 6 . There was no difference in the $M_{w}$ and $M_{n}$ values for the opaque and clear regions in irradiated PCL observed after testing (see Section 3.2).

\subsection{Cell growth curves}

It appears, from the results in Figure 4, obtained by flow cytometry, that bovine chondroprogenitor cells grow equally well on PCL that has been sterilised by gamma 
irradiation, soaking in ethanol or a combination of the two methods. This is quantified, for flow cytometry, in Table 7. The slopes of the graphs in Figure 4 are a measure of the cell growth rates. Since the $95 \%$ confidence intervals of these rates are the same for all three sterilisation methods, it appears that gamma irradiation does not adversely affect the proliferation of the cells on PCL.

\section{Discussion}

GPC indicates that gamma irradiation breaks PCL polymer chains but also causes some cross-linking. The number-average molecular weight, $M_{n}$, decreases (Table 6), i.e. the average molecular weight of an average polymer chain decreases [17]. This result can be explained by chains being broken. However, the weight-average molecular weight, $M_{w}$, increases (Table 6), i.e. some chains have a higher molecular weight [17]. This result can be explained by cross-linking. The observation that gamma-irradiation cross-links the polymer chains is consistent with irradiated PCL having a higher tensile strength (Table 4). It is also consistent with the results of Masson et al. (1997) who showed that gamma irradiation (at $2.5 \mathrm{Mrad}$ ) increased $M_{w}$ in PCL nanospheres; they attributed this observation to cross-linking of polymer chains [8]. Narkis et al. (1984) showed that gamma irradiation, at a much higher dose (26 Mrad) than required for sterilisation led to chain scission and cross-linking [7].

Irradiation significantly decreases the rate of degradation of PCL (Section 3.1). Substituting the results from Section 3.1 into equation 3 of the appendix, we find that, in our experiments, irradiated PCL degrades at a rate of $5.1 \mathrm{mg} . \mathrm{s}^{-1}$ and that untreated PCL degrades at a rate of $6.4 \mathrm{mg} . \mathrm{s}^{-1}$, after $1 \mathrm{~s}$ of degradation. However, the exact 
values of the rate depend on both initial mass of PCL and degradation time (see equation 3 of the appendix). In our experiments, the PCL samples eventually stopped degrading, i.e. the polymer and its degradation products reached an equilibrium mixture. In vivo, the degradation products would be expected to be cleared from the body so that degradation would proceed to completion. The early degradation rate, in our experiments would be similar to the rate that would be observed when the degradation products were cleared, because the concentration of degradation products would be low.

Although the comparison of degradation rates, for irradiated and non-irradiated PCL, is valid, the absolute values of the degradation rates are much greater than would be observed in vivo. This is because lipase was added to catalyse the degradation in our experiments to enable them to be completed in a realistic time. There is no suggestion that lipase normally catalyses the degradation in vivo. Lipase catalyses the hydrolysis of the bond between a carbonyl group and an oxygen atom in fats. This is exactly the same bond that is broken during normal hydrolysis of PCL [18]. Therefore, addition of lipase causes PCL to degrade by the same mechanism as normal but more rapidly. The effect of irradiation appears to be to break the PCL chains and to introduce crosslinks. There is no reason, from the magnitude of the changes in $M_{n}$ (in Table 5) to suspect any substantial changes in the chemistry of the polymer. Then the rate of degradation of irradiated PCL, relative to the rate for non-irradiated PCL, is expected to be very similar when the reaction is catalysed by lipase and when it is not.

Gamma irradiation has a significant effect on the mechanical properties of PCL. It increases the yield stress, i.e. the stress at which the material ceases to respond 
elastically and becomes plastic. It also increases the failure stress, when the failure mechanisms are considered separately but not when they are combined (see Table 4).

Finally, the cell growth studies showed that gamma irradiation of PCL does not prevent cells from attaching and growing on its surface. Cells appear able to grow equally well on PCL surfaces that have been sterilised by irradiation or with ethanol or by both methods simultaneously.

\section{Acknowledgements}

We thank Isotron, Daventry for irradiating the PCL samples and Rapra Techonolgy, Shropshire for the GPC analysis. EC was supported by an EPSRC doctoral training account. 


\section{Appendix}

It appears, empirically (see Figure 1a), that the mass, $m$, of PCL is related to the hydrolysis time, $t$, by

$$
m^{1 / 2}=k t^{1 / 2}+m_{0}^{1 / 2}
$$

where $m_{0}$ is the initial mass of PCL and $k$ is a constant.

The rate at which PCL hydrolyses is obtained by differentiating equation 1 with respect to time:

$$
\begin{aligned}
& \frac{1}{2} m^{1 / 2} \frac{d m}{d t}=\frac{1}{2 t^{1 / 2}} \\
\Rightarrow \quad \frac{d m}{d t} & =k \sqrt{\frac{m}{t}}
\end{aligned}
$$

From equations 1 and 4, the rate of degradation is given by

$$
\frac{d m}{d t}=k \frac{k t^{1 / 2}+m_{0}^{1 / 2}}{t^{1 / 2}}
$$




\section{References}

1. Gan Z, Liang Q, Zhang J, Jing X. Enzymatic degradation of poly( $(\varepsilon-$ caprolactone) film in phosphate buffer solution containing lipases. Polymer Degradation and Stability 1997;56:209-213.

2. Hutmacher DW, Schantz T, Zein I, Ng KW, Teoh SH, Tan KC. Mechanical properties and cell cultural response of polycaprolactone scaffolds designed and fabricated via fused deposition modeling. J Biomed Mater Res, 2001;55:203-216. 3. Xu Q, Ren XW, Chang YN, Wang JW, Yu L, Dean K. Generation of microcellular biodegradable polycaprolactone foams in supercritical carbon dioxide. J. Appl. Polym. Sci 2004;94:593-597.

4. Wang F, Shor L, Darling A, Khalil S, Sun W, Guceri S, Lau A. Precision extruding deposition and characterization of cellular poly( $€$-caprolactone $)$ tissue scaffolds. Rapid Prototyping J 2004;10:42-49.

5. Hill D. Design engineering of biomaterials for medical devices. Chichester: Wiley; 1998.

6. Sintzel MB, Schwach-Abdellaoui K, Mader K, Stosser R, Heller J, Tabatabay C, Gurny R. Influence of irradiation sterilization on a semi-solid poly(ortho ester). International Journal of Pharmaceutics 1998;175:165-176.

7. Narkis M, Sibony-Chaouat S, Siegmann A, Shkolnik S, Bell JP. Irradiation effects on polycaprolactone. Polymer 1985;26:50-54.

8. Masson V, Maurin F, Fessi H, Devissaguet JP. Influence of sterilization processes on poly(caprolactone) nanospheres. Biomaterials 1997;18(4):327-335. 
9. Pena J, Corrales T, Izquierdo-Barba I, Doadrio AL, Vallet-Regi M. Long term degradation of poly (caprolactone) films in biologically related fluids. Polymer Degradation and Stability 2006;91:1424-1432.

10. Coombes AGA, Rizzi SC, Williamson M, Barralet JE, Downes S, Wallace WA. Precipitation casting of polycaprolactone for applications in tissue engineering and drug delivery. Biomaterials 2004;25:315-325.

11. Harrison KL. The effect of supercritical fluid processing and physical properties on the role of polycaprolactone as a biodegradable tissue scaffold used to promote in vitro chondrogenesis [PhD]. Birmingham: University of Birmingham; 2004.

12. Malero-Martin J, Dowling M, Smith M, Al-Rubeai M. Optimal in-vitro expansion of chondroprogenitor cells in monolayer culture. Biotechnology and Bioengineering 2005.

13. Graff RD, Kelley SS, Lee GL. Role of pericellular matrix in development of a mechanically functional neocartilage. Biotechnology and Bioengineering 2002;82(4):457-464.

14. Al-Rubeai M, Welzenbach K, Lloyd DR, Emery AN. A rapid method for evaluation of cell number and viability by flow cytometry. Cytotechnology 1997;24:161-168.

15. Givan AL. Flow cytometry; First principles. Wilmington: Wiley-Liss; 1992. 16. Zwietering MH, Jongenburger I, Rombouts FM, van't-Riet K. Modelling of the bacterial growth curve. Applied \& Environmental Microbiology 1990;56:18751881.

17. Cowie JMG. Polymers: Chemistry and physics of modern materials, second edition. London: Chapman and Hall; 1991. 
18. Sivalingam G, Chattopadhyay S, Madras G. Solvent effects on the lipase catalysed biodegradation of poly( $($-caprolactone $)$ in solution. Polymer Degradation and Stability 2003;79:413-418. 


\section{Figure Captions}

Figure 1. Degradation of PCL for irradiated (broken line) and non-irradiated (continuous line) samples: (a) mass of PCL discs plotted against degradation time and (b) the square root of the mass of PCL discs plotted against the square root of the degradation time. In (b), the square of the linear correlation coefficient, $R^{2}=0.99$ for both lines. Each data point is the mean of eight measurements; error bars represent standard deviations.

Figure 2. Scanning electron micrographs of PCL after degradation (264 h): (a), (c) and (e) are from irradiated samples; (b), (d) and (f) are from untreated samples. Magnifications of the original micrographs were: 25 (a and b), 50 (c and d) and 250 (e and $\mathrm{f}$ ).

Figure 3. Schematic stress-strain curve obtained from tensile testing a sample of PCL. In this figure, the yield point, $\mathrm{A}$, is defined as the point of maximum stress before irreversible deformation takes place. The failure point is defined as the point at which the sample breaks. Non-drawn samples remain wide at their ends, which remain opaque, while the central region becomes transparent and fails at a point around B. Drawn samples become transparent throughout, their ends are drawn into the centre and they fail at a point around D. Part-drawn samples show intermediate behaviour or appear drawn at one end and non-drawn at the other; they fail at a point around C.

Figure 4. Cell growth on PCL measured by flow cytometry. Filled circles are results for samples sterilised by irradiation, filled squares are for samples sterilised with 
ethanol and open circles are for samples sterilised by both techniques. All data points are the mean of two replicates. Results are analysed in Table 7. 


\section{Tables}

Untreated Irradiated

Drawn

11

7

Non-drawn

4

5

Part-drawn

4

5

Total

19

17

Table 1. Results of tensile testing; numbers of specimens failing by the mechanisms defined in Figure 3 and the total numbers. 


\begin{tabular}{lccc}
\hline & Untreated & Irradiated & $p$-value \\
\hline Drawn & $10.2(2.1)$ & $14.8(2.3)$ & 0.001 \\
Un-drawn & $9.0(2.2)$ & $13.0(1.4)$ & 0.033 \\
Part-drawn & $8.4(1.7)$ & $13.8(1.7)$ & 0.003 \\
All samples & $9.6(2.1)$ & $14.0(1.9)$ & 0.000 \\
\hline
\end{tabular}

Table 2. Yield stress (MPa) for irradiated and untreated PCL (standard deviation in brackets) for each of the failure modes defined in Figure 3. A p-value of less than 0.05 denotes a significant difference between results from irradiated and untreated samples. 


\begin{tabular}{lccc}
\hline & Untreated & Irradiated & $p$-value \\
\hline Drawn & $0.17(0.01)$ & $0.18(0.01)$ & 0.169 \\
Un-drawn & $0.13(0.04)$ & $0.17(0.03)$ & 0.085 \\
Part-drawn & $0.15(0.04)$ & $0.18(0.02)$ & 0.210 \\
All samples & $0.16(0.03)$ & $0.18(0.01)$ & 0.180 \\
\hline
\end{tabular}

Table 3. Yield strain for irradiated and untreated PCL (standard deviation in brackets) for each of the failure modes defined in Figure 3. A $p$-value of less than 0.05 denotes a significant difference between results from irradiated and untreated samples. 


\begin{tabular}{lccc}
\hline & Untreated & Irradiated & $p$-value \\
\hline Drawn & $45.0(6.4)$ & $49.9(2.9)$ & 0.044 \\
Un-drawn & $26.2(0.8)$ & $33.9(5.6)$ & 0.040 \\
Part-drawn & $33.7(1.7)$ & $42.3(3.5)$ & 0.005 \\
All samples & $38.7(9.4)$ & $43.0(7.8)$ & 0.145 \\
\hline
\end{tabular}

Table 4. Failure stress (MPa) for irradiated and untreated PCL (standard deviation in brackets) for each of the failure modes defined in Figure 3. A p-value of less than 0.05 denotes a significant difference between results from irradiated and untreated samples. 


\begin{tabular}{lccc}
\hline & Untreated & Irradiated & $p$-value \\
\hline Drawn & $16.6(0.9)$ & $19.1(0.2)$ & 0.000 \\
Un-drawn & $9.8(0.8)$ & $11.9(1.7)$ & 0.057 \\
Part-drawn & $13.7(0.4)$ & $15.6(0.8)$ & 0.003 \\
All samples & $14.6(2.9)$ & $15.5(3.5)$ & 0.180 \\
\hline
\end{tabular}

Table 5. Failure strain for irradiated and untreated PCL (standard deviation in brackets) for each of the failure modes defined in Figure 3. A p-value of less than 0.05 denotes a significant difference between results from irradiated and untreated samples. 


\begin{tabular}{lccc}
\hline & $M_{w}$ & $M_{n}$ & Polydispersity \\
\hline Irradiated & $2.18 \times 10^{5}$ & $7.9 \times 10^{4}$ & 2.77 \\
& $(0.05) \times 10^{5}$ & $\left(0.1 \times 10^{4}\right)$ & $(0.01)$ \\
Untreated & $2.02 \times 10^{5}$ & $9.9 \times 10^{4}$ & 2.04 \\
& $\left(0.02 \times 10^{5}\right)$ & $\left(0.1 \times 10^{4}\right)$ & $(0.01)$ \\
\hline
\end{tabular}

Table 6. Weight average, $M_{w}$, and number average, $M_{n}$, molecular weights for irradiated and untreated PCL. Each result is the mean of four measurements (standard deviations in brackets) performed by gel permeation chromatography (GPC). The polydispersity is defined to be $M_{w} / M_{n}$. 


\begin{tabular}{lccc}
\hline & Irradiation & Ethanol & Both \\
\hline$R^{2}$ & 0.87 & 0.90 & 0.86 \\
Slope & 0.94 & 1.01 & 0.94 \\
LCI & 0.69 & 0.67 & 0.60 \\
UCI & 1.2 & 1.1 & 1.1 \\
\hline
\end{tabular}

Table 7. Analysis of results from flow cytometry, for cells growing on PCL sterilised by gamma irradiation alone, ethanol alone and both methods combined. The data were analysed by linear regression. The square of the linear correlation coefficient, $R^{2}$, shows how well the data points fit a straight line. The slope of the line measures cell growth (per day); the lower (LCI) and upper (UCI) confidence intervals associated with this slope are tabulated. 
Figures

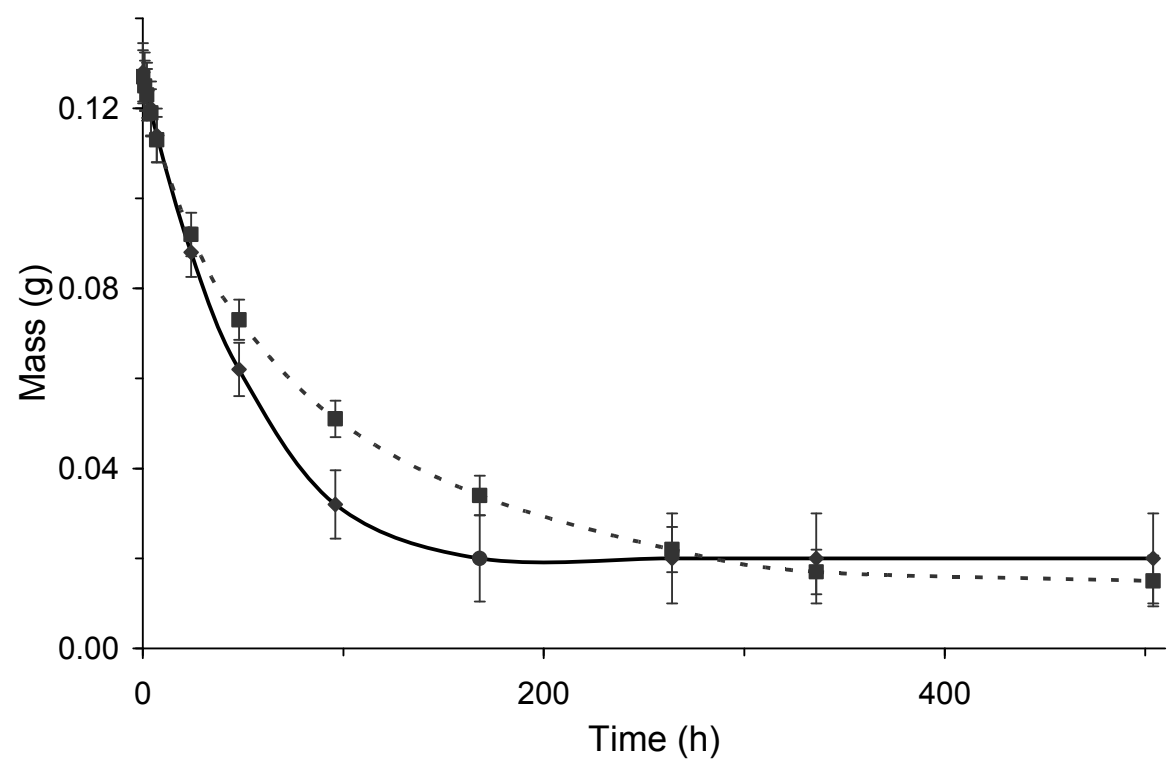

Fig. 1(a)

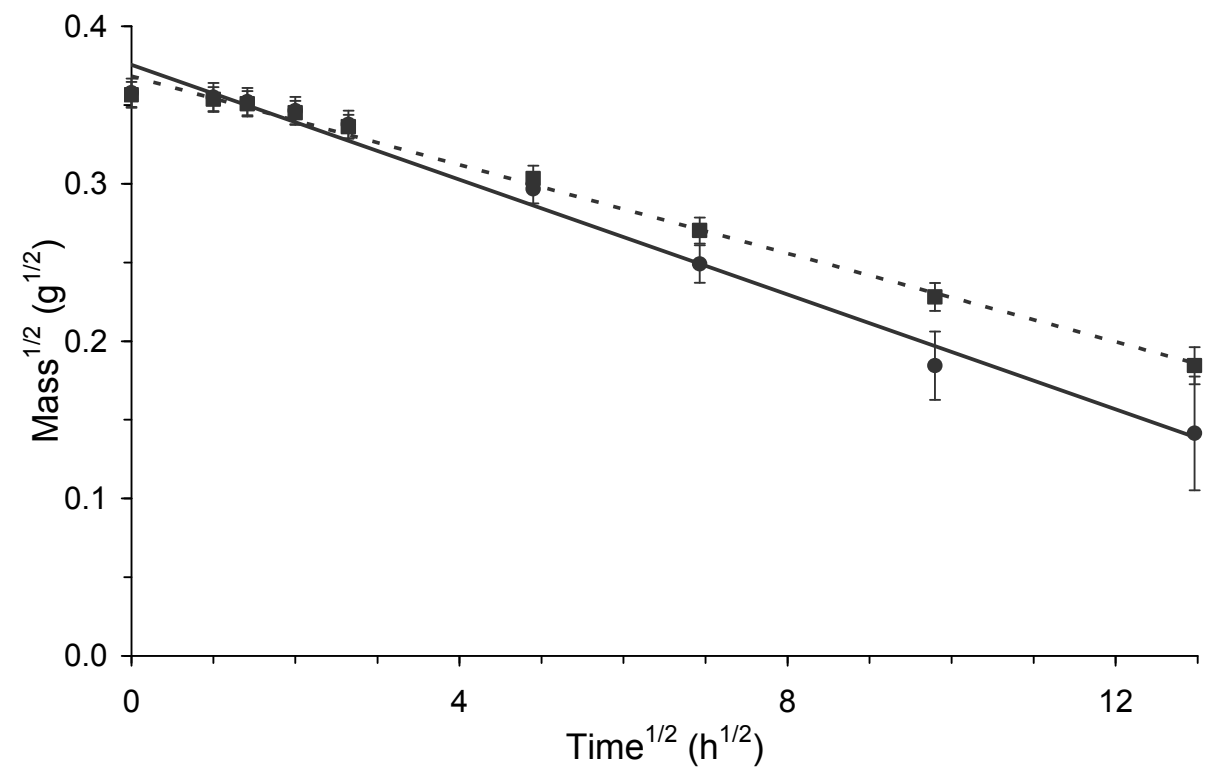

Fig. 1(b) 


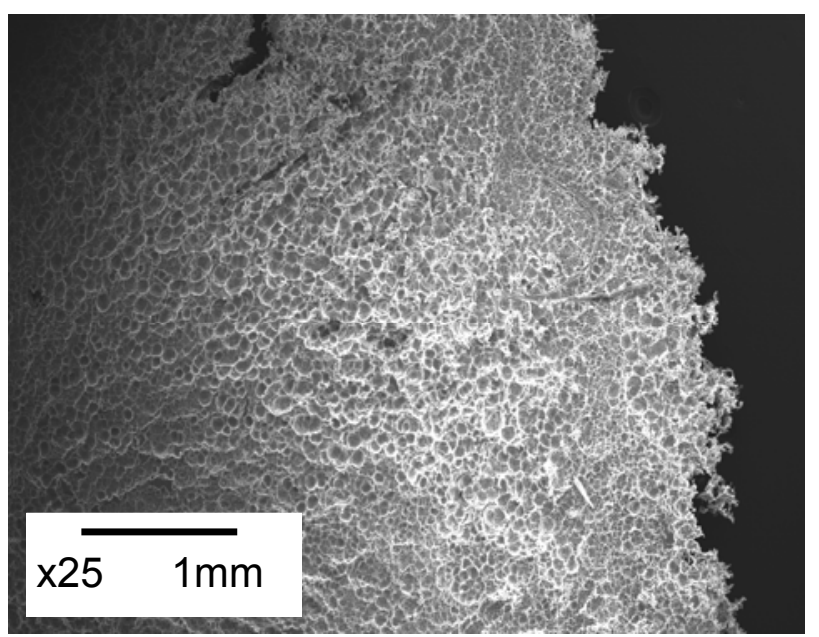

Fig. 2(a)

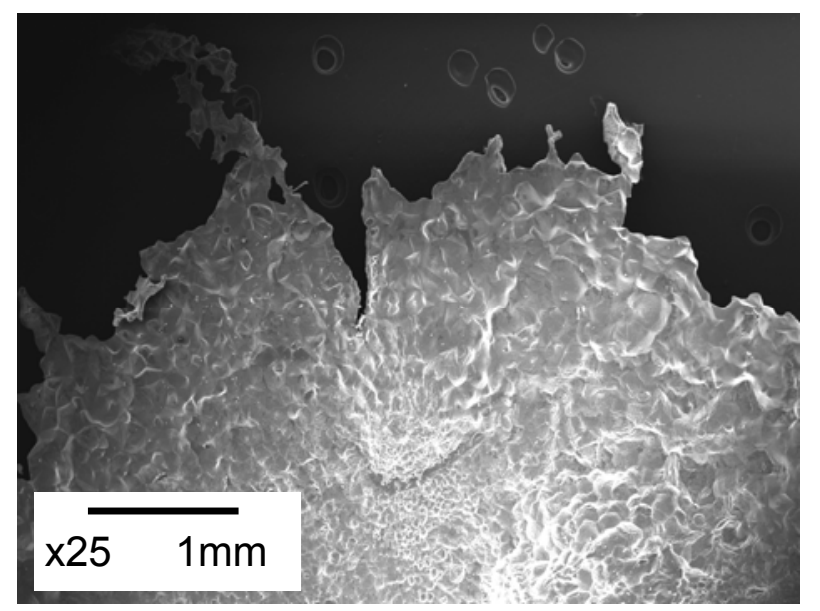

Fig. 2(b)

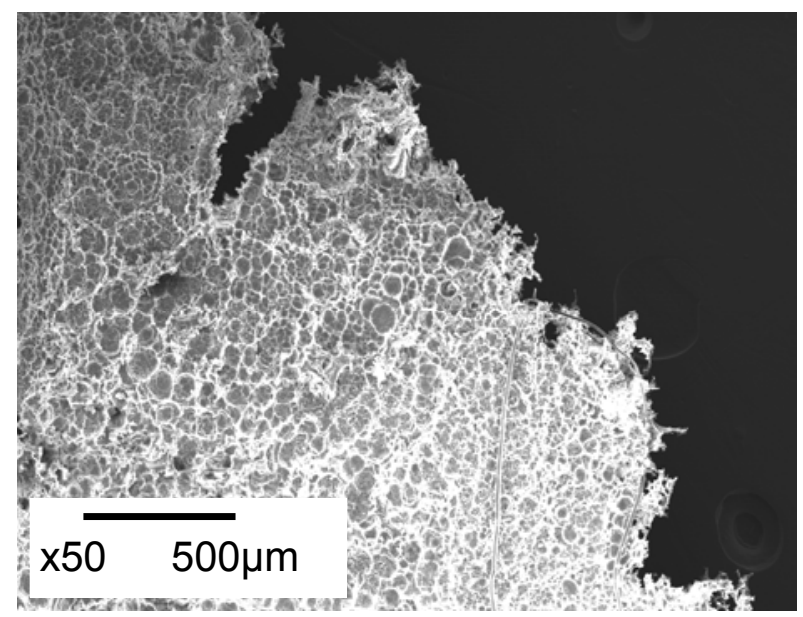

Fig. 2(c) 




Fig. 2(d)

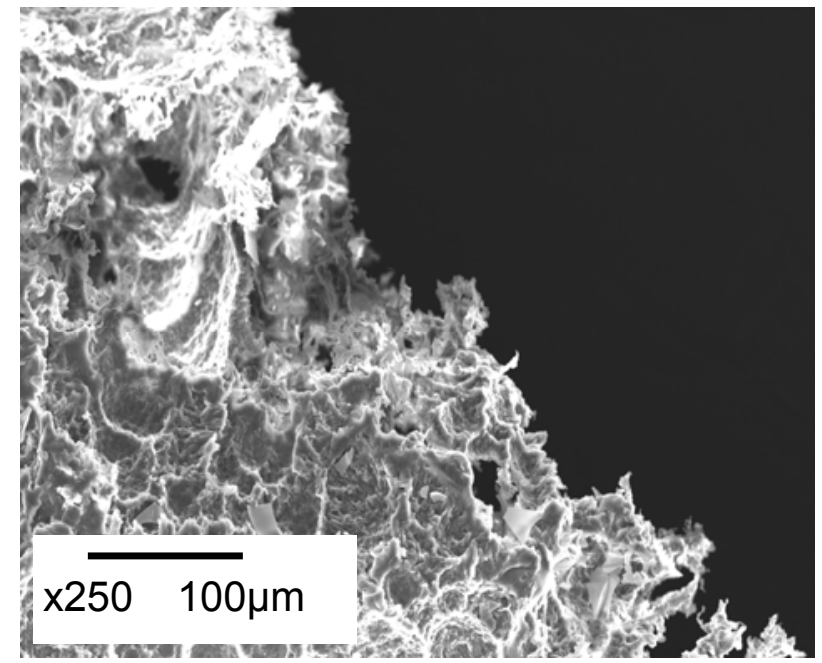

Fig. 2(e)

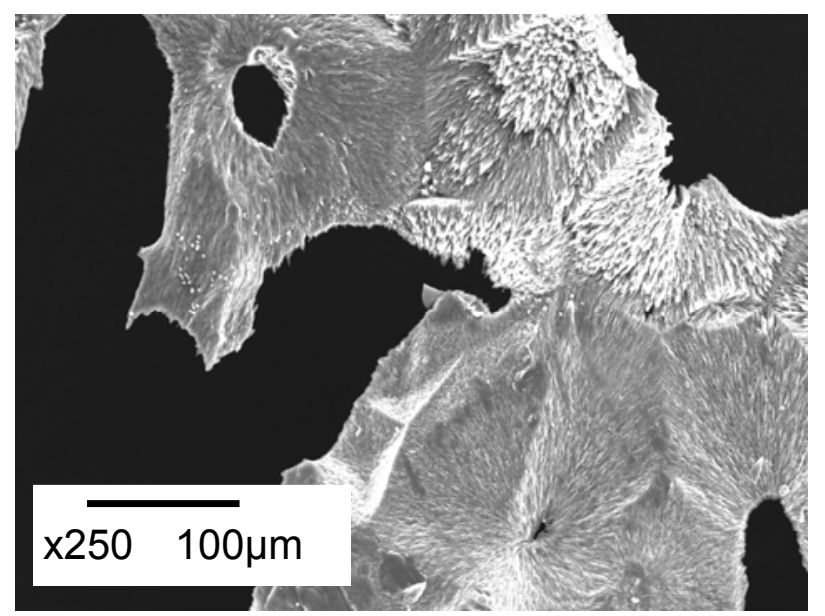

Fig. 2(f) 


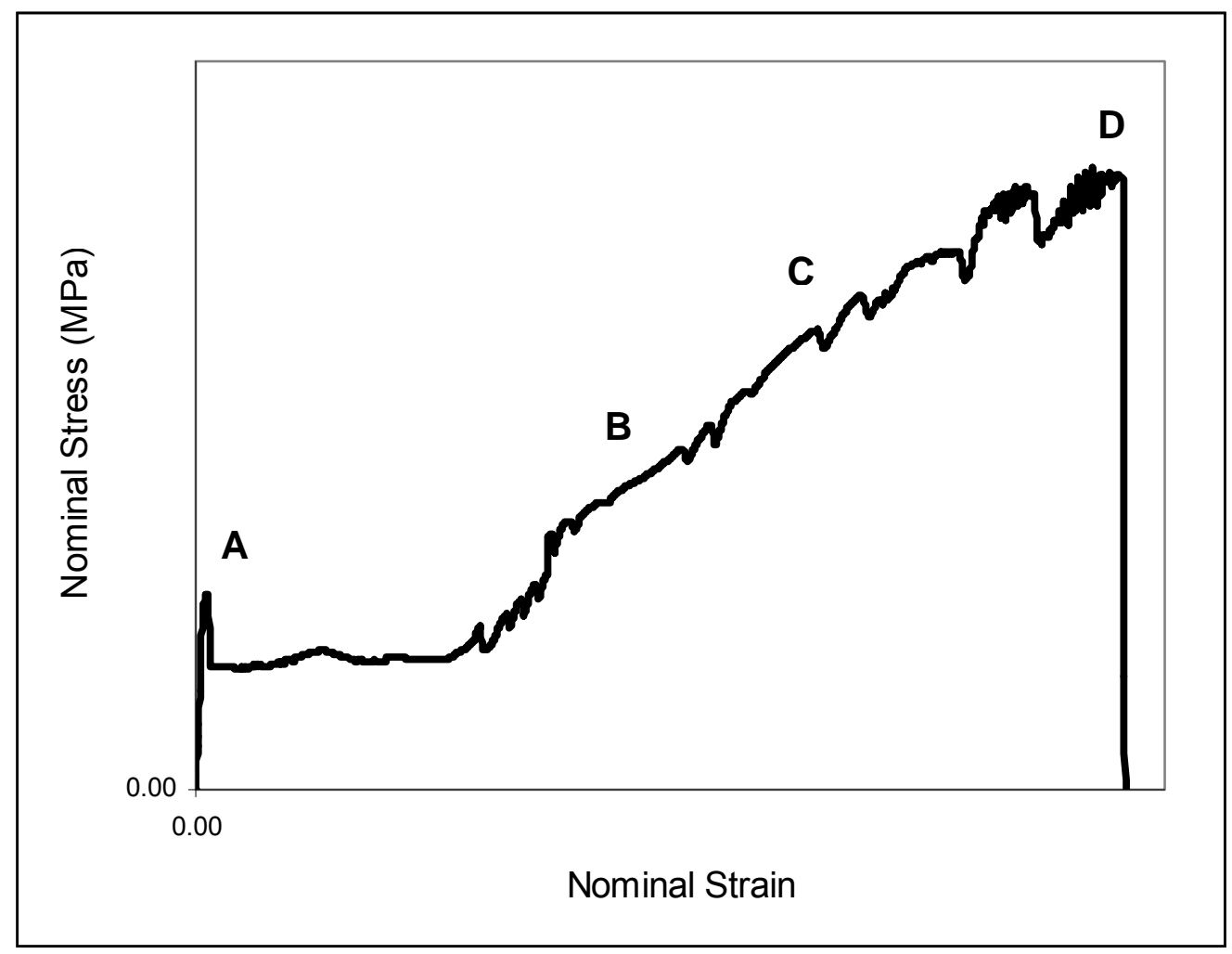

Fig. 3

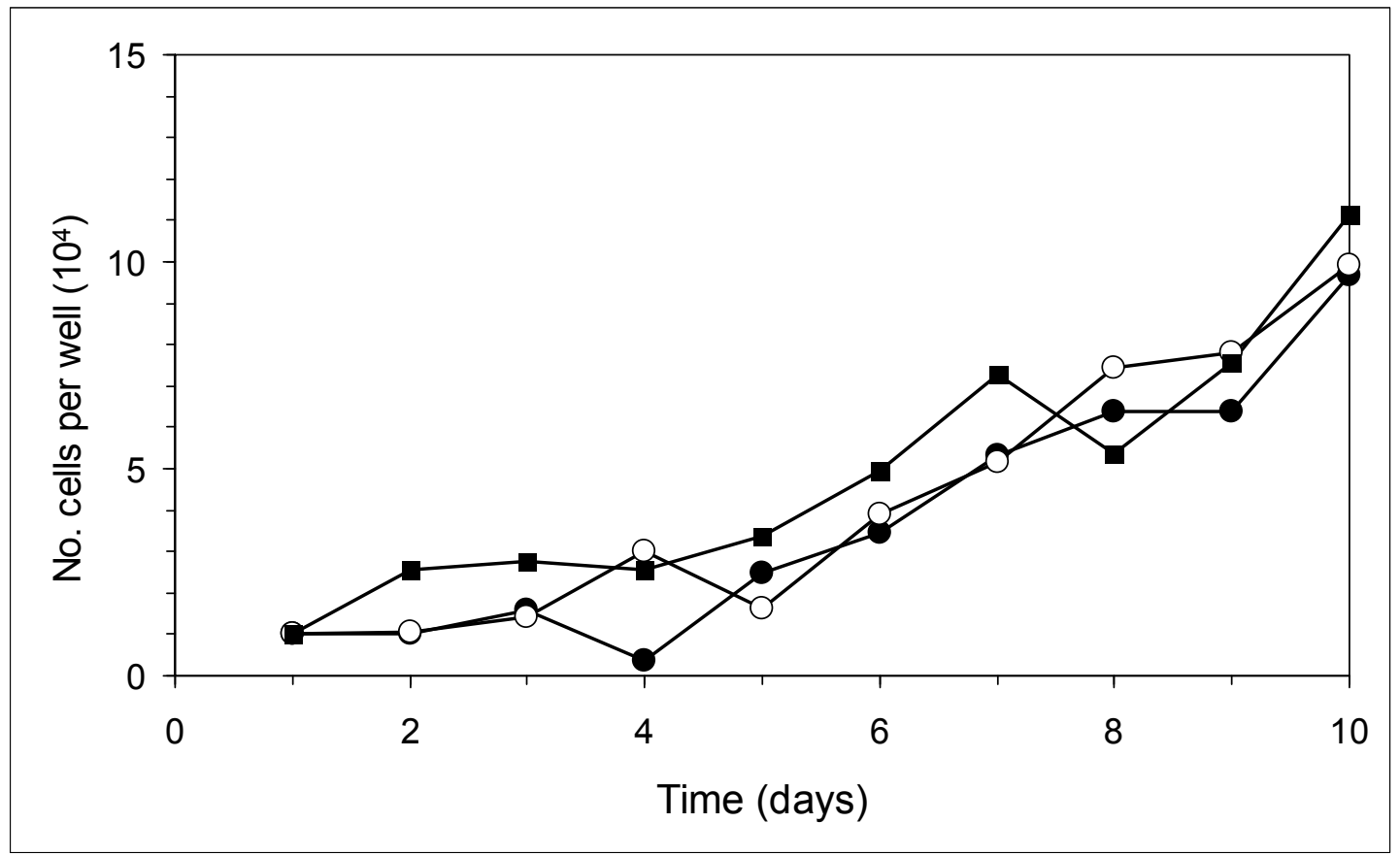

Fig. 4 